\title{
WestVirginiaUniversity
}

THE RESEARCH REPOSITORY @ WVU

Graduate Theses, Dissertations, and Problem Reports

2001

\section{Teaching Web design at the higher education level}

\author{
Randall Franklin Mull \\ West Virginia University
}

Follow this and additional works at: https://researchrepository.wvu.edu/etd

\section{Recommended Citation}

Mull, Randall Franklin, "Teaching Web design at the higher education level" (2001). Graduate Theses, Dissertations, and Problem Reports. 1259.

https://researchrepository.wvu.edu/etd/1259

This Thesis is protected by copyright and/or related rights. It has been brought to you by the The Research Repository @WVU with permission from the rights-holder(s). You are free to use this Thesis in any way that is permitted by the copyright and related rights legislation that applies to your use. For other uses you must obtain permission from the rights-holder(s) directly, unless additional rights are indicated by a Creative Commons license in the record and/ or on the work itself. This Thesis has been accepted for inclusion in WVU Graduate Theses, Dissertations, and Problem Reports collection by an authorized administrator of The Research Repository @ WVU. For more information, please contact researchrepository@mail.wvu.edu. 


\title{
Teaching Web Design at the Higher Education Level
}

\author{
Randall F. Mull
}

\author{
Thesis Submitted to \\ The Perley I saac Reed School of Journalism at \\ W est $V$ irginia University \\ in partial fulfillment of the requirements \\ for the degree of
}
M aster of Science
in
Journalism

Ivan Pinnel, Ph.D

Robyn Blakeman, M.A.

Kurt Schimmel, Ph.D

Carol Zwickel, Ph.D

\author{
P.I. Reed School of Journalism \\ M organtown, W est Virginia \\ 2001
}

Keywords: web design, html, technology introductory course 


\section{ABSTRACT \\ Teaching Web Design at the Higher Education Level}

\section{Randall F. Mull}

For the latter half of the last decade the new phenomenon known as the Internet has taken over media and journalism in many ways. It has changed the way that news and information is delivered to the public. It has made people also perceive the media in a new way. The public now, more than ever, demands information fast and accurately.

That is why it is critical that students of journalism today learn about this new tool which they can use to their advantage. In order to address this need within the P. I. Reed School of Journalism a new course was taught in HTML and web design, Journalism 191-K Intro to HTML and Web Design. The class was taught using the Behavioral-Engineering model. This model subverts feelings of anxiety over computer related material, by introducing it in a slow methodical manner. Handouts and computer time where used as a main source to implement the model. Students were evaluated in various manners including tests assignments and a final project. The research done prior to the class itself was to determine two main factors, what constitutes a well designed web-site, and what is the best way to teach students. This was done through researching various articles in a literature review. Through the research, I found that web design is a class that can be taught easily and successfully in the manor mentioned above. Also discovered, was that students respond favorably to the aspect of new technology and have no problem tackling new territory or subject matter. 


\section{TABLE OF CONTENTS}

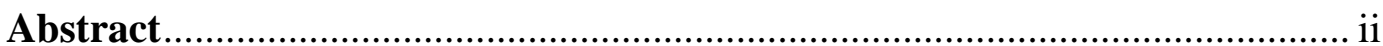

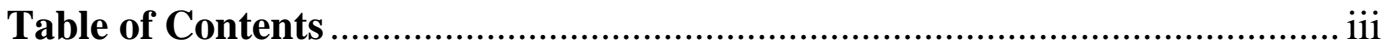

Introduction

Statement of the Problem and Justification ...............................................1

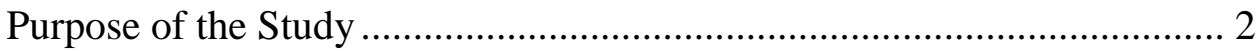

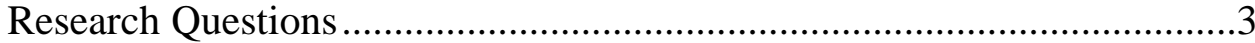

\section{Literature Review}

Creating Well Designed Web-Sites ........................................................4

Techniques for Teaching Web Design

and Student Teacher Relationship

\section{Methodology}

Design of Methodology ...................................................................20

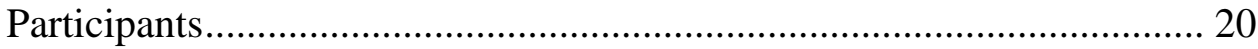

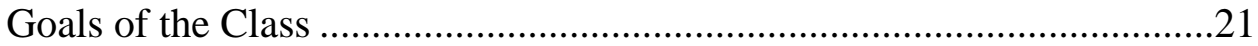

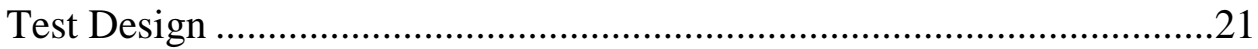

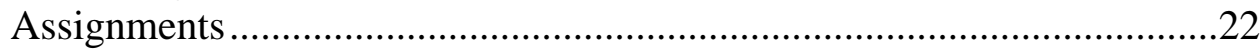

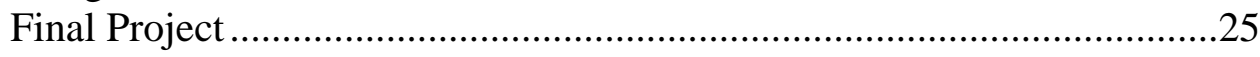

Teacher Student Relationship ..........................................................26

\section{Findings}

Teacher Student Developments .......................................................29

\section{Conclusions}

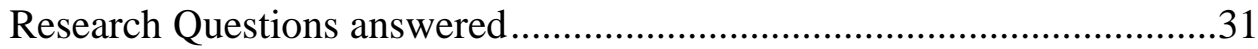

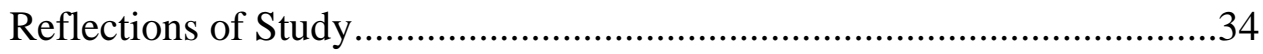

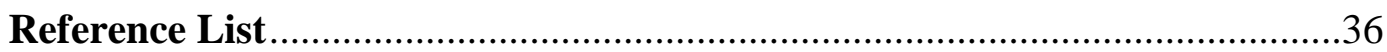

\section{Appendix}

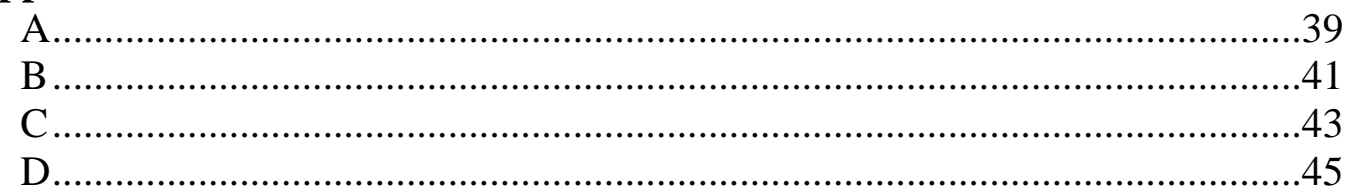

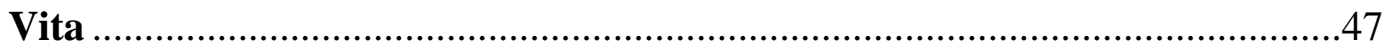




\section{Introduction}

The 1990's will be remembered as the period the Internet became a prevalent force in mainstream society. It has come on like a hurricane and swept the world off its feet. Individuals that are familiar with its concepts and inner workings are one step ahead of the rest of society. Those individuals that can create web-sites and design are purveyors of new technology and knowledge. The Internet has become a necessity in today's business world. Virtually every company or organization has a web-site to help convey information about themselves and their purpose within the business world.

Hence, it has become imperative at the college level to have a course taught in the area of HTML, HyperText Markup Language and web-design. Because the Internet touches every aspect of the media, it is important in a journalism setting Journalists, no matter what type advertising, public relations, broadcasting or news editorial, have always been among the first to bring new ideas and news to the public. The Internet now provides these people with a new vehicle to transmit their message. Therefore, it is vital that students understand and learn this new form of technology so that they can be the conveyors of tomorrow's messages. The lessons that they learn in the classroom will better prepare them for their future in the field, of journalism.

\section{Statement of the Problem and Justification}

Because HTML and web-design are such new concepts to most of society, it is not readily understood by many people and may seem like an impossible concept to master. In recent years, there has been a generation gap between those who can master these techniques and those who tend to shy away from them. Most children who are in 
high school and elementary school now have no problem with these types of programs because it is something they are growing up with and are exposed to everyday. However, for the rest of the population, it is an invention that has been thrust upon us which some are not willing to accept.

As a result of the Internet's vital role in the journalism community, it is critical to HTML and web-design to students whenever possible. Therefore, college-level courses should be taught on the subject to prepare students to compete in the job market with rapidly changing technology.

\section{Purpose of the Study}

For this study, I will examine what techniques can be taught to college students to give them a better grasp of HTML and web-design. I also want to discover if these techniques are feasible to teach to students. Since not all web-design techniques are uniform and since there are several different ways to present, display, and create web pages, the teacher must determine the most effective way to teach students these techniques. Also, to be determined is what criteria, which designates a good web page as opposed to a bad one. Obviously, there are varying and different opinions on this matter, but an overall consensus and wisdom should prevail.

Another aspect of this study is to determine what kind of teacher-student relationship is appropriate to help facilitate the best learning experience possible. This is a topic that is usually left to the discretion of the individual teacher. However, in recent

years, studies have been conducted which show certain teaching practices are more beneficial to the student's and teacher's learning experience. 


\section{Research Questions}

The questions asked in this research were obtained in two different manners. First, previous research compiled on the subject was reviewed. Since the Internet and web-design have grown in popularity over the last six-to-seven years, this narrowed the research considerably. Second, studies focusing on teacher-student relationships and what can be gained from these relationships, both personally and professionally, were examined. Original research was also conducted through developing and teaching the course. This study focuses on answering the following questions.

Q1: What techniques are best suited to teach class and convey information to students in a way that they can get the maximum benefit?

Q2: Generally, what attributes and standards should be applied to every web-site to optimize its capabilities?

Q3: Through student feedback and my own self-examination, am I suited for a teaching career in the academic world? 


\section{Literature Review}

Meeting the challenge of web design should be approached with caution. A welldesigned web-site materializes without proper training, even though many individuals who upload them onto the Internet seem to think so. Designing a web site is, to a great extent, a form of art. Like all art there are some techniques that are proven to work better than others. This literature review attempts to reveal, the techniques work best. Also this literature review will attempt to determine which what teaching techniques are best suited to reach the students when working with computers and programs that are foreign or new to them.

\section{Creating Well Designed Web Sites}

Michael Schuyler's, “The Future of Web Design," deals with the controversy of "flashy" web sites with sound and graphics versus more traditional web design that is text only. Schuyler is a pioneer of web design and was one of the experts at its inception. In the article, Schuyler describes the history of web design and what it has become today. One particular problem that Schuyler points out is the problem of making web sites accessible to individuals with disabilities. The persons with disabilities would be those that are vision or hearing impaired. Web content and accessibility have been incorporated into legislation. This is a law that was introduced via The Americans with Disabilities Act (Schuyler 2000, 50). This aspect of web design should be taken into consideration.

Schuyler concludes that in today's work world, one must have sufficient experience to create a well-designed web-site or one should not attempt the endeavor (Schuyler 2000, 50). 
Schulyer contends that a middle ground should be provided between high-tech web sites that use Java script, or flash 4 and those that are simple text based web-sites. Schulyer's reasoning is that for disabled persons, especially vision impaired, the use of Java script can throw off programs such as JAWS which aid vision impaired people to surf the Internet (Schuyler 2000, 50). However, these same individuals do not want a boring text driven web-site that does not allow them to use their imagination. That is why it is vital for companies or individuals to use software or web-sites that will evaluate their site to manage such problems.

The main theme that can be obtained from this article which will be incorporated into the proposed class is that each web site should be designed to be assessable to the hearing and vision impaired. There are sites on the Internet that allow one's web site to be rated on the basis of whether it is user-friendly. In the proposed class, after the students have finished with the design of their web site, each site will be tested to see how they fare as being disability acceptable. After a web-site is uploaded onto the Internet the HTML content can be sent to an Internet site called NetMechanic. The website checks the individual's HTML for such thinks as load time, link breakage and accessibility to vision and hearing impaired individuals.

"HTML is key, but Design Skills and Teamwork are Also Vital", written by Johnan Rindegard, discusses the key importance of learning HTML, along with other web design programs. Rindegard points out that the use of HTML and learning graphic design go hand-in-hand (Rindegard1999, 69). The article also points out that learning such programs as Photoshop allow an individual to learn concepts such as color and space usage. 
However, Rindegard makes it clear that HTML background knowledge is key in any web design. Many times web editing programs may not produce the right results. The individual must then go back, using HTML, to fix the problem. An example would be text not centering, or the wrong colors being displayed for a graphic or background. Therefore, to prepare the students on proper use of the computer programs such as Photoshop and Quark will be taught in the proposed class before delving into HTML. This should give the students a higher sense of orientation with the computers, and instill in them a higher level of confidence in developing their HTML and web skills. The instruction of Photoshop and Quark will also help students with some aspects of design that they will need to design their web-sites.

"Predictors of Internet Use" deals with the "attraction" aspect of what holds Internet surfers to certain sites and why they return to that site. The hypothesis of the researchers was similar to previous media research when pertaining to television and radio. It is that individuals use the Internet for six major motives: pleasure, affection, inclusion, escape, relaxation and control (Papachrissi 2000, 176). In their methodology, 279 students were used for a survey about the usage and the reasons for Internet use.

The researchers discovered that five factors, interpersonal utility, pass time, convenience, entertainment and information seeking drove individuals to use the Internet. There was no significant difference between male and female users (Papachrissi 2000, 185). The survey also revealed the factor influencing entertainment and information seeking. The main factor was the updating of news or information pertaining to the subject of the web site. This referred to any subject, from music group sites to comic book fan sites. This not only provided information for the user, but also kept them 
entertained with updates and kept the web site fresh. This was not what the researchers thought that they would find, they hypothesized that individuals use the Internet like most media however, as the study indicated that was not what the results of this study showed.

This aspect will be applied when teaching the proposed class. In the content portion of the class, students will be informed that in order to keep their web sites fresh, innovative and exciting, their site must be maintained and updated on a timely manner. A timely manner could be defined as whenever news becomes available. If no news or updates become available for more than three days then this should be stated in the website that news or updates are slow at the moment. Information should be updated as soon as it becomes available. Rumors should never be spread as "official" news. Much like a reporter at a newspaper or magazine. As the above study shows this is prevalent no matter what subject their web- site covers.

Another article dealt with the interesting subject of Online Fanzines and what they do to attract and keep users. In this study, Matthew J. Smith studied several successful comic book fanzines and interviewed their creators to find out what determined their success.

Smith found several aspects of these sites helped them stay ahead of their competitors, even those in the print media. In the previous study, "Predictors of Internet Use," it was stated that information must be timely and current so it keeps users interested and wanting to return to the site. Smith also found that unlike usual written text, the internet can allow users to move more easily from one topic to another, or to the specific topic of their choice with little or no effort (Smith 1999, 91). This was due mainly to the layout of the web-site and its overall design. 
According to Smith, a third aspect that made these web sites very popular was interaction with its users. Users were encouraged to write in and give their opinions on the site and its content. Smith found they were also asked to contribute to the site, if possible, by submitting articles or information that was news worthy (Smith 1999, 93).

A fourth factor is using familiar symbols in the content of the web site. An example given in the article would be that of Superman's S shield. This would automatically let users identify the web site's content. Symbol usage is a predictor and indicator of the content of a creator's site. However, one does not want to alienate new users to the site. Therefore, it is good to have links to related or official sites to show something that may be more familiar to the user. This keeps both the new and old user happy (Smith 1999, 93).

In the course students will be shown the relevance of having a connecting symbol or phrase that will let the surfer know what the web-site is about. Also the importance of interaction will be stressed, in the form of having contact information available on the students' web-sites.

"From On-Air to Online World: Examining the Content and Structures of Broadcast TV Stations' Web Sites" the researchers examined the different features that TV stations applied to their web sites to try and enhance them. The researchers hypothesized that interactivity would be the key to a higher level of web surfer use. The researchers performed a content analyze of 300 broadcast TV stations' web sites (Ohmsted 2000, 325). All HTML code to create the site was collected from each web site and saved on a central computer for analyzes. A set of criteria was used to identify 
well-designed web sites. They were as follows: appearance, content linkage, special feature, structure and use.

The researchers discovered that ease of use, ease of navigation and overview of overall structure were most important (Ohmsted 2000, 327-328). Examples of these would be as follows; being able to obtain news fast and easy by being able to locate it. Having information such as the weather, presented in a way that was similar to the graphics used in the nightly news broadcast. The feature that was most important and central to almost every web-site was that of the front-page news on the site. This aspect became the "center piece" of the site and the main attraction. However some of the web sites used linkage as the main source of attraction. This could be to either their mother affiliate site or another web site important to the subject area.

In the proposed course, the importance of having a site that incorporates all of the aspects found vital to a successful news site will be incorporated. The significance of having a main attraction, or centerpiece, that will hold the user's attention and keep them from straying from the site at first glance will be stressed. This could be in the form of a headline used to catch the surfer's attention. Another attention holder would be that of an opening page that immediately let's the web surfers identify what the page is about.

"Does Web Advertising Work? Memory for Print vs. Online Media" examines subject of advertising on the web and whether it was more effective than that of traditional print media. The researchers conducted a study with 48 student subjects. Each subject was given a fictitious newspaper headline with two stories and one advertisement. Half of the subjects read the page in newspaper form while the other half read it in online 
form (Sundar 1998, 825). The subjects were then asked a set of questions to examine their memory recall of the page both in story and advertising content.

The results revealed that the subjects were much more likely to remember advertisements from print media than online web sites. This is true even though subjects were equal in their memory of story content for both print and online source (Sundar 1998, 828-829).

The researchers came to several conclusions. First, since the Internet is a new media form it may be true that individuals are not yet conditioned to respond to the advertisements that they see in an online format. Another conclusion of the researchers was that because the Internet is used for more specific purposes than other types of media, the advertisements may be seen as intrusive. The reason being that the online forum is still seen as a free, unpackaged market. Therefore the viewers only look at the central information while they pay little to no attention to the advertisements (Sundar 1998, 829-830).

In a more recent article, "The Future of Advertising" published by Tom Lowry and Gerry Khermouch, it has been shown that advertisements on the Internet have almost no impact on the individual surfing the net. As a result many advertisers are now shying away from the Internet (Khermouch 2001, 138). Top companies such as McDonalds, Volkswagen and Anheuser-Busch no longer use advertisements on the Internet. Instead, they are using television to draw people to their sites. Another way that companies are using advertisements on the web it to actually incorporate them into the site. Also many sites are letting advertisers create ads in new shapes and sizes instead of the usual pop-up window or square box (Khermouch 2001, 138). 
The role and placement of advertisements on websites will be discussed in the proposed course. Students will look at different sites and compare advertisement use. How to design and place these advertisements will also be shown so the students know what ways they can be placed within a web-site.

In another study, "Interactivity Reexamined: A Baseline Analysis of Early Business Web Sites", the researchers took a look at past business web sites and compared them for interactivity with users and what aspects of the site made them interesting. The researchers wanted to answer four main questions: Which dimension of interactivity was more prevalent in early business web sties? How did business sites fair in interactivity? When did a high level of interactivity occur_-before or during a web site visit? Were there significant differences between business types and their interactivity scores? (Ha 1998, 461).

The researchers conducted a content analysis of 110 web sites that had three types of business services: manufactured goods, services and retail outlets. The web sites were then put into four categories that the researchers found vital to a business web-site: (1) playfulness and choice, having games or colors on the web site; (2) conceitedness, many of the sites were self promoting; (3) information collection, finding out information about visitors to the web site and (4) reciprocal communication, explained below.

The researchers found that the most important aspect of a business web-site was that of reciprocal communication, individuals visiting the web-site could communicate with the company and vise versa (Ha 1998, 468-469). This was mainly used as a tool for selling products, but not in every case. It was also used to take comments on complaints and customer satisfaction about the company and their web site. It became a central key 
to the success of the web sites because it kept the company in touch with the pulse of their customers.

The aspect of reciprocal communication will be stressed in the content of the proposed class. This is a useful element to a web site that seems like common sense, but can sometimes be over looked. It should be noted that the above article also pointed out that different categories should be presented easily for the user. For example, a category should be given for complaints, both for the company and the web-site itself. This makes it easier on the customer navigating the site and for the creator of the site as well. I will stress the importance of this layout scheme to my students. This should be seen as both a communication and layout skill. The categories should be labeled in a way that makes it easy for the surfer to navigate to the communication pages easily.

"Integration of Internet Resources into Curriculum and Instruction" dealt with the aspect of using Internet resources and applying them to teaching within the classroom.

The main concern in this article was how the integration of the Internet as a tool can either help or hinder the learning and teaching process in a classroom.

The two researchers attended a workshop at the Poynter Institute for Media Studies in 1995. The workshop was on introducing Internet resources into the classroom. Twenty instructors were at the workshop. Afterwards, the researchers kept in touch with their fellow instructors via e-mail. They did so to see if the instructors had incorporated the Internet as a tool and if so how successful it was. As of the following fall, half had incorporated some type of Internet use into their classroom teaching. Only one had developed their own web-site that individual had been taught HTML and web-design by one of his students. (Gunaratne 1996, 26-27). 
Thus, the researchers decided to slowly integrate aspects of the Internet into three of their own journalism classes in the fall semester: reporting, copy editing and international communications. These were conducted in 50-minute lab sessions. The students were introduced to different aspects of the Internet such as e-mail, HTML, etc.

The researchers were able to draw several conclusions. First, a problem arose if the student already knew how the program worked and therefore became bored with the instruction. It also became a problem if the students were taking the same classes into which the tools were being integrated. Thus, a solution to these problems was devised: a beginner's workshop, which closely resembles the course I am proposing. The researchers also concluded that students benefited greatly from having a working knowledge of the Internet and the different ways it could help them in their research and future job position.

This concept will be taught in the proposed class to students who will review the different aspects of the internet and how they can be used to benefit not only the web-site that they will be designing but the research they will need to design it.

In Sandra Davidson Scott 's article, “The Technological Challenge for Curriculum and Instruction", it became clear that the problem of teaching new technologies in journalism schools was not being addressed by teachers. She decided to conduct a telephone poll of 254 journalism and mass communications instructors. The sample was taken from the Association for Education in Journalism and Mass Communication. Those individuals who exclusively taught advertising or public relations were excluded from the sample. 
The subjects were asked two basic questions: what are journalism and mass communication schools doing well and what are journalism and mass communication schools doing poorly? They were then given several categories from which to choose. These categories included research, job placement, new technology training, etc. (Scott 1995, 30-31).

In the area of new technology training, the conclusion was that students were not being taught enough in this area. Many of the instructors surveyed suggested that more time be spent on training not only students, but also faculty, in the area of new technologies. The study also found that the graduates with the most technology training were the ones who were in highest demand (Scott 1995, 33-35). Scott's research found, many professors responded in their survey that more funding in the way of staff and equipment was needed in order to conduct new technology classes. Many of the professors suggested that perhaps internships in technology driven work places could solve this problem, if no further funding could be made available (Scott 1995, 35).

This article helped lend credibility to the argument that a class in web design, new technology and basic computer skills are crucial to the success of job placement and preparedness for journalism students. Therefore, a class in HTML and web-design will fit well into the current curriculum within the P. I. Reed School of Journalism at West Virginia University.

\section{Techniques for teaching web design, and Student Teacher Relationship}

“The Teacher-Student Relationship as an Interpersonal Relationship" pertains to the relationship between a teacher and a student, and how that relationship can lead to 
better teaching and learning. The two researchers main question was in regard to effective teaching; what do students find important in regards to communication skills and immediacy behaviors (Frymier 2000, 207-208)?

The method of their research was to study 93 subjects and ask them how important eight different types of communications skills and non-verbal skills were to good teaching. The sample was split into 32 males and 61 females. The eight skills were rated using a 7-point scale that was rated between "very important" and "very unimportant." These skills included: ego support, conflict management, referential skill regulative skill comforting and persuasion. In the second study, a set of 257 subjects were chosen 79 males and 177 females and one person not identified. In this study, the students were asked to rate the teacher who they had just had in their previous class. The same scale was used as in the first study. The exception this time was that the students were asked to report how well the teacher used the skill listed.

The results of the first study showed that all of the categories had means above 4.0, except for comforting, which fell below. This indicates that the students felt these items were important in successful teaching.

The second study revealed that females found communication and immediacy behavior more linked to learning than males. However, males and females were impacted equally by the communication skills of the teacher that would be how well the teacher conveys the class material to the students. If the teacher did not communicate properly to the students they, of course, found it difficult to learn and understand. The communications barriers in this study that the researchers found were due to lack of verbal communication between the teacher and student. This could be in the form of 
misinterpretation of material, for example, the teacher not explaining the information thoroughly enough for the student to understand.

The researchers concluded that it was easier for both the students and teachers once they have reached an interpersonal relationship because they could feel comfortable to ask, "dumb questions" in situations that may seem awkward to a student with no interpersonal relationship. This benefits higher levels of learning such as analysis and synthesis (Frymier 2000, 215).

This article has shown the importance of interpersonal relationships and the need to communicate and speak freely with students.

In the article, “Attitudes of Professors and Students About New Media Technology", Jane Singer and her fellow researchers looked at the attitudes of teachers and students toward the aspects of new media. Forty -two subjects ranging in age from 19 to 67 were chosen for the study. Thirty-five indicated that they used the Internet and e-mail on a regular basis.

The subjects were asked forty-eight questions or given statements that they were asked to rate on an eleven-point scale. The questions pertained to the subject of new media and the individuals' views and opinions of the subject. Some of the sample statements were: the possibilities created by new media technology are exciting, the new media will call for different ways of teaching people how to write and work for the media (Singer 1996, 37).

After the study was conducted respondents were put into four assigned categories. These categories were as follows: Champion of Change, the Pessimistic Prophet, the Laid Back Liberal and the Skeptical Optimist. Briefly described, the Champion of Change is 
excited about new media and wants to incorporate it in to their world. The Pessimistic Prophet's greatest fear of new technology is that it will be used to control the individuals that use it. The Laid Back Liberal views new media as a problem but not to the extent of the Pessimistic Prophet. They do not believe that the technology could control the individual. Instead they believe that individuals will not be able to access the new technology any time soon on a wide scale basis and therefore it is not yet a threat. The Skeptical Optimist wants new technology to change the world but does not believe that it will. The individual likes the idea of change but believes that it may be changes not necessarily for the better. For example, the information obtainable for both rich or poor will not narrow but actually widen, as those without the ability to afford new technology will be left behind (Singer 1996, 42-43).

Overall respondents to the study believed that new media technology was not the end of their journalism careers. Many did not even see it as a threat to their job, but instead saw it as a way to enhance it. The main goal of this study was to understand how journalists would use and respond to new technology in the future, and how they would use it to communicate to their audiences (Singer 1996, 44).

This article relates to the class in a very unique way. It illustrates the future of journalism and how willing journalists are in embracing technology. One of The goals of my class will be to introduce and enhance my student's understanding of the technologies that are currently reshaping the journalism profession. By doing so they will be on the cutting edge of their profession and may be willing to try new technologies that come in the future. This aspect of the class will keep them from being the Pessimistic Prophet and the Skeptical Optimist. The way that this will be approached in class will be to 
encourage students in areas that they may decide they do not want to try, or do not think they can do properly. This will be prevalent in the HTML portion of the class. Since this is a new concept to many of them they may feel unsure of learning. Through exercises in class I want to keep them from becoming skeptical or pessimistic. They will be guided slowly through the lessons to hopefully change their view of what HTML and the Internet can be used for. A recent article written by Diane M. Dusick explores the factors that influence professors' use of technology in the classroom, and what theories and techniques they use to teach their classes. In the study Dusick examined the theory known as self-efficacy, this theory states that individuals try to avoid anxiety-causing situations by preparing or not preparing themselves for the project. In computer related programs this can come from not knowing, or not being familiar with a certain type of program. Dusick also pointed out that verbal encouragement and computer experience will not "cure" computer anxiety (Dusick 1998, 126).

It was discovered that individuals that had a bad experience with a certain program were more likely to experience computer anxiety. To solve this problem two things were needed, simplified instruction and computer time. This could be easily achieved in a class setting as long as the time was taken to implement the program. Several environmental factors contributed to individuals using computers and what they learn from them: availability of computers in the classroom, support and sharing of resources, training, competence, time, and lack of knowledge.

An attempt can be made to control these factors through the Behavior Engineering Model. To enact this model some factors must be worked into the classroom setting. 
This would include supportive teaching, capable software and time taken for individual needs (Dusick 1998, 129).

The study proposes a four-step process to introduce technology into the classroom to improve the use of technology by not only the teacher but the student as well. Stage one identifies potential computer use and requires a low level of computer literacy, Stage two applying learning theories to computers providing hands-on experience. Stage three evaluates computer techniques and materials used to improve computer skills, Stage four reviews computer management and forms of assessment (Dusick 1998, 130).

The end result however, is it is up to the individual teacher or student to make themselves take the time required to learn the new material and apply it. Self-motivation is something that can not be taught and unfortunately is required heavily in these situations. 


\section{Methodology}

The current study examines the way in which web-design and HTML are taught to students at the undergraduate level. Several aspects are covered in this model, including how the material is presented, how the students react to it, what materials are presented, and, finally, what is taught. The study also covers the interaction and relationship between student and teacher.

\section{Design of Methodology}

To carry out the study, a class was designed within the P. I. Reed School of Journalism. The class was entitled 191-K, Introduction to HTML and Web-design. It was a three-credit class offered to undergraduate students that had taken 191-J or PR 119 as a prerequisite. Because of these two prerequisites, several students were already familiar with the material that was being presented to them. This made the study easier to conduct because the students knew what to expect, to a certain extent, and were not caught off guard. Students were evaluated by four assignments, four tests and a comprehensive final project.

\section{Participants}

There were a total of sixteen students enrolled in the class, fifteen seniors and one junior. No students dropped the class, so each student counted as a participant. 


\section{Goals of the Class}

1. Introduce the students to the basic operation and function of the Macintosh computers and operating system they would be using throughout the semester.

2.Introduce the use and function of two popular journalism-intensive application programs: QuarkExpress, desktop publishing and Adobe Photoshop, photoediting program.

3.Introduce basic web design concepts as HTML and a web-design editor, Adobe ImageStyler.

4.Decide if teaching at a college level is a suitable career path for me in the future.

\section{Test Design}

Four tests were presented to the students to evaluate their knowledge of the material presented to them during the course of the semester. One test was given for each section of the course. One for Quark Express, (desktop publishing program), Adobe Photoshop, (desktop publishing program), HTML code used to create all web- sites, and Adobe ImageStyler, a web-editing program that designs web-sites. All tests consisted of fifteen questions, and each test was worth 45 points. The questions on the test were ones that asked the students to identify basic operations on the specific programs. Questions tested how well the students knew the many components of each application program.

The tests were given to test and help the students understand the basic operations of the programs. The applications of the programs to actual projects would be tested in the assignments and final projects. 
Three bonus questions were given on each test. These questions pertained to material outside the class. For the second through fourth tests questions of 1980's television trivia were presented.

They were used for two reasons; first, it was a way for the students and I to connect. Second, many of the students looked forward to the questions and it was a fun way to break the pressure and stress of a test. One aspect should be noted about the bonus questions: the age of the students a five-year difference in age between myself and my students revealed similarities in our educational background. I was able to find out I had a lot in common with them.

The students benefited greatly from the tests. Most of the students scored high marks on all their tests. Which was a great benefit to me because it let me know that I would be able to move on to actually applying the operation, instead of going over the operation of the program itself.

\section{Assignments}

The students were also given three take-home or in-class assignments. Each assignment, like the test, was given on one of the four programs taught during the semester. These assignments were to study how well the student could apply their knowledge of the program to a real-life situation.

For example, after being taught Quark Express, the students were asked to create a brochure using the program. This assignment was chosen not for the benefit of HTML, and web application but for layout and design purposes. The Quark assignment was also designed to help the students become more familiar and comfortable with the computers. 
The students were asked to create a brochure based on a fictious company that I created. The company was called (ASAP), The Association of Salmon Against Ivan Pinnell. For the exercise the students were asked to import two pictures, have one paragraph be of a different color text, and have a cut away order form.

The assignment worked well to test the students' Quark skills but not their lay out or design skills. I had already designed the brochure so the students were able to apply the knowledge they had obtained from the Quark lessons. However, they were not able to use their imagination to design the brochure. Because learning design and layout for future web design was a main point for the exercise it was in some respects a failure. If the lesson were used again I would give the students guidelines to follow, but let them use their imagination to design the brochure.

For the HTML section of the class, the students were asked to create a two-page web-site. This assignment was a preliminary introduction into what their final web-site, later designed on Adobe ImageStyler might look like. For this assignment the students could base the two pages on the web-site that they would be creating. In order to assess if they had learned the proper techniques in the HTML lessons they were given the following guidelines. They had to make the background of another color besides white. The color of the text must be visible and readable against the background that they chose. They were asked to create one heading and one sub-heading. They were also asked to create an un-ordered, and ordered list. The students were asked to give three links to pages that related to their site. A navigation bar was also to be placed on the first page or the second page if the first page was an opening graphic of some sort. The last two criteria were to create a table and import a graphic of some type. 
This assignment worked very well and aided in teaching the students the basics

of HTML. Because many web design programs may run behind or not interface with some HTML design which is constantly being changed therefore, knowledge of HTML is important to fix the mistakes made by these programs.

The next assignment was to design and layout on paper what the students' website would look like. The students were asked to draw each page of their web-site on trace paper. I would then discuss the project with them and see if what they wanted to do would be suitable and realistic with their current skill level.

This assignment did not exactly turn out how I thought it would. I did not give the students enough guidelines to follow before doing the assignment. Some students went as far as coloring in background and graphics, while other students simply drew boxes where certain objects or colors would go. If this assignment were given there would have to be guidelines set. These would include; coloring or stating what type of color would be used for backgrounds and graphics also numbering each page and stating what its proper place was within the web-site as a whole. The main purpose of this assignment was to get the students prepared to think about what their web-site would look like and what they wanted the site's content to be about.

Overall, the use of the assignments was very beneficial to the lessons of the class. They did in fact, assess the knowledge of the students in trying to apply the programs. Although minor adjustments need to be made if these assignments are to be used again in a class setting they were still a success. 


\section{Final Project}

The final project in the class was to design a web page of the students own choosing. The reason they were not asked to create a more standardized web page that had certain guidelines set up beforehand was that it might, possibly, have stifled their enthusiasm for the project. After examining the project this aspect may not have been the correct thing to do. The reason for this is that it was harder to grade the students against each other. Their creativity would have been easier to examine and grade because they would have been set within a certain parameter to work with. The students could work in groups of two or three if they wished to do so. Many of the students felt more comfortable doing this because if they were weak in a certain skill their partner could do this part better. The students had to follow the these criteria to complete their web-site:

- Have at least three pages to their web-site.

- Have an opening page, with a symbol or logo that would catch a web surfer's attention in some way that is related to the content of the page. An example from the literature review would be the S symbol shield from Superman.

- Have a theme or symbol running throughout the web page that allowed individuals to identify the subject of the web page with the web page itself.

- Have at least three links to other web pages that were related to the content found on their web page.

All of the preceding guidelines were instructed to the students earlier in the semester, during two lectures. All of these aspects of web design and layout were taken from research discovered in the literature review. 


\section{Teacher Student Relationship}

During the course of the semester, a study to see how well students reacted to certain criteria and stimulation was also conducted. After-class discussions and conferences held during the middle of the semester were the main points of interaction outside of class time. During these times, a relationship was being cultivated that made the students feel comfortable with what they were doing. Some of the students did not feel comfortable with the work that they were doing in the class even though the class average was in the high B range. An interpersonal relationship was formed between the students and I. The students were treated as equals and not like they were less competent or less knowledgeable than the instructor. The students were instructed repeatedly to ask questions at any time and told that they could rely on the instructor to help them in any way possible. However, a book, HTML for Dummies, was provided to keep the students from taking advantage of the instructor's time when working with the web-sites. Also, sufficient class time was given each week to allow students to ask questions. This enabled the students to feel more comfortable with themselves and the instructor as well.

It was very important for the students to learn more freely and to feel more comfortable to ask questions, especially with a subject so new to most of them. Only two students in the class had previously designed a web-site, not using Adobe ImageStyler, so this was a foreign program. Therefore, it was important that the instructor be available for the students. Several manuals were also provided on the final project for the students to look through if they had any questions. These manuals were the ones provided with the Adobe ImageStyler program. They have a tutorial in the beginning that explains 
basic operations and in-depth functions. These manuals were beneficial in case a student wanted to perform something that was not covered in class. This prevented the students from having to ask the instructor to repeat information already covered in class. The students should not have needed to use the manuals, however they were provided. 


\section{Findings}

In preparation for the class, I designed several handouts for each computer program being taught. The students could use these as a guide. The handouts also worked well in allowing me to have a step-by-step method of teaching the program. The handouts were designed in a logical order that allowed for the program to be taught skill by skill. The handouts could be used as a visual aid, allowing me to move around the room more freely without having to be the main focus as the head of the classroom.

There was only one class where an actual lecture was given, which the class was set up in the more "traditional" method of teacher lecturing and student taking notes. Instead, the lectures were set up in a way that the material and computer programs dictated the pace and content that was taught. More or less time could be spent on a given topic, depending on the students' grasp of the content.

If a student wanted to learn more than the handout provided at the end of class the instructor could show the student how to operate this part of the program. This happened only two to three times during the course of the semester.

The programs being taught were of a hands-on nature and, to be learned, had to actually be utilized and executed. Simply lecturing and, then, letting the students use the programs was not enough for them to learn. The students were taught each aspect of a program as they went. Once an aspect was taught it was applied. This let the students learn the programs slowly, and was therefore more effective, then teaching them several operations at once and then letting them apply them an hour after they had heard what to do. This made the class move smoother and allowed for fewer questions. Also, the point must be made that this was simply an introductory course, and the students were not 
asked to master the programs presented to them. The true point of the course was to give the students a working knowledge of the programs that they could explore themselves or learn to apply more when taught in an upper level class.

I believe that the technique used to teach the students was successful. The students responded positively to the handouts. Before starting a new program, many students would ask with a look of hope on their faces, "Is there going to be a hand-out?" The students felt more secure, as did I, because, when doing assignments on their own, they did not use me as a crutch to answer questions for them. They simply had the material and information in front of them to use instead. It was also useful for me because, if I forgot something in class that I wanted to inform the students of, it was usually covered in the handout. The handouts' clear and concise information made them a valuable tool.

The handouts were also used to supplement the material that they learned in lecture and from the tests. When doing assignments or the final project the handouts were strictly used as reinforcement, in the same way a textbook would be used.

\section{Teacher Student Developments}

The most positive aspect of this study was the relationships cultivated with many of the students in the class. I found that at the end of the semester, that there was an aspect of mutual respect between the students and myself. As discovered in the literature review, this is an important factor when teaching any class. This focus became a very important aspect to the class. It gave the students, as well as the instructor, a sense of freedom to say and do things not in other classes. A lot of this, I believe, had to do with 
my age and the fact that I am still a student myself. I do not know if the same approach would work for an older teacher, but I believe that it could. It is up to the instructor to establish the relationship that they desire, with each relationship being different with each student. I found that as long as a certain level of genuine caring is shown for each student, they respond with respect for the instructor as well.

This aspect made the course flow much easier and made my first time as an instructor much easier. I was hoping that with this approach, I would be able to achieve these results, and my hypothesis worked out correctly. I do not think that this kind of relationship could be achieved with a large class without a tremendous amount of work being undertaken by the instructor. I believe that it would be up to that individual whether that type of approach could be used or would be appropriate.

I found that the students all learned a great deal during the course of the semester. The average in the class was a high $\mathrm{B}$, which is not an unusual average for an upper-level class, but I was pleased, since it was my first time teaching a course. I believe that the students learned valuable skills that they will be able to apply to their careers. The class will also help in any courses that may have similar content, and material. 


\section{Conclusions}

At the end of the semester and the completion of the course, I was able to reflect on the three research questions that shaped the focus of this new course. I also learned many beneficial steps to take to ensure a positive learning experience.

\section{Q1: What Techniques are best suited to teach class and convey information to students in a way that they can get the maximum benefit.}

The best way to convey computer techniques to students is through the behaviorengineering model. Through this model, the students were given simplified instructions that enabled them to grasp the technology quicker and easier. The students were also given ample computer time to hone their skills and ask questions which pertained to the subject matter. Supplemental material, in the form of handouts prepared for each class, greatly aided the learning process. Also a fair amount of class time was given each week for attention for each student or group of students.

\section{Q2: Generally, what attributes and standards should be applied to every web- site to optimize its capabilities?}

There are several key factors, which should be addressed on each web-site. First, the web-site should have a key element or symbol on each page that lets the user know what the content of the web-site is about. Second, pages in a web-site should be arranged in a way that is easy for the user to navigate. This can be achieved through the use of a navigation bar, on the introductory page of the web-site. Third, and most important, information on a web-site should be updated as constantly as is allowable. That is to say when news or information pertaining to the subject of a web 
site is available it should be put on the site immediately. Also, material on a web-site, both text and images, should be displayed in a manner that is easy to read and understand, and also conform to specification designated for those with disabilities.

\section{Q3: Through student feedback and my own self-examination, am I suited for a teaching career in the academic world?}

This is the one question that at this point is unanswerable. I am not yet sure if education is a career path that I may pursue later with more intent. I believe more class time and experience would be necessary to more thoroughly make that magnitude of a decision. I do believe that it is a very valuable experience and one that has been very beneficial as far as educating others and developing my interaction skills.

I think that after working for several years I will be better suited to answer this question, after I have experienced more aspects of life in general.

Student feedback to my teaching style and class material was very positive. Many students made several comments that for teaching for the first time I was doing a good job. At this time none, of the student evaluations have been returned so true student response is unobtainable.

Aside from answering the three research questions that were tested and answered throughout the semester, many ideas and observations were developed and observed that would make future classes better for both the instructor and the students. Below are five guidelines I believe to be most important.

1. Teaching an introductory level class on a relatively new subject to the academic world should be properly planned out beforehand. A sound approach must be 
taken in order to achieve successful results. Good planning will solve problems before they develop. Of course it is impossible to be prepared for everything. If I were to teach this class again, I would of course do things a bit differently. First, I would make sure that the proper guidelines for each assignment were thought out before hand. For two of the assignments, the Quark Express and preliminary drawings of the web-site, more thought should have been given to guidelines. Also, more thought to helping individual students. Each student learns in a different way and the handouts may not have benefited all of them. Although the style of teaching incorporated were both visually and audio stimulating it may have not caught every student. More research should be done to help these types of students learn.

2. Students are more responsive to a teacher-student relationship that is one of mutual respect. It helps teach the class content and allows the students to learn in a more accelerated manner.

3. The normal enthusiasm of college students allows them to explore and test new technology, such as web-design and HTML. Although intimidating at first, they have no trouble taking on new subjects or methods and adjusting very easily.

4. Because the Internet has become such a vital part of today's world, especially in the work force, it is imperative that it be taught to college students. These techniques will add valuable skills to their repotoir and make them more attractive to perspective employers. 
5. Teaching new technology that is innovative and fresh gives the P.I. Reed School of Journalism at West Virginia University a level of respect that is, not only good for the school, but also for the students that graduate from it.

\section{Reflections of the Study}

I found teaching this class to be very challenging and rewarding beyond anything that I could have imagined. I have newfound respect for teachers everywhere, not only on the university level, but the high school and elementary levels as well. People do not realize all that goes into preparing and teaching a class. I thoroughly enjoyed teaching a subject that was new and exciting to the class and the world. It was better than going over a theory or subject that has been around for a long time. This teaching style accepts adoption of ideas instead of following set-in-stone formats.

The students came out of this class well prepared for more advanced instructions in the subject of HTML and web design. The goal of the class was not to make them masters of these concepts, but to simply introduce them to it. I believe that many of them would be able to create a well-constructed web-site, if asked to. They may have to refer back to class material in order to do so, but they could get the task done.

The most valuable lesson I learned was not about HTML, web design, or teaching, but rather the students themselves. They are up for absolutely anything if they can enter the class in a flexible, open-minded manner. Many people in today's society dismiss students and young people. However, if one looks closely, they are often the ones that are teaching us. 
I feel very strongly that a class of this nature should be continued after I receive my Master's Degree and move on. I believe that it would be better suited to freshman and sophomores, the reason being that it is an introductory course, and there are no concepts or theories being introduced. Only the tools and functions of the programs needed to carry out these concepts in later classes should be taught. Overall, the class was successful beyond what I could have imagined. With this experience now behind me, I look forward to some day returning to the academic world and becoming an instructor once again. 


\section{Reference List}

Dusick, Diane M. 1998. What Social Cognitive Factors Influence Faculty Members' Uses of Computers for Teaching? A Literature Review. Journal of Research on Computing in Education. (Winter) : 123-138.

Frymier, Ann Bainbridge, Marian L. Houser. 2000. The Teacher-Student Relationship as an Interpersonal Relationship. Communication Education 3 (July) : 207-219.

Gunaratne, Shelton A., Byung S. Lee. 1996. Integration of Internet Resources in Curriculum and Instruction. Journalism and Mass Communication Educator 1 (Spring) : 25-35.

Ha, Louisa, E. Lincoln James. 1998. Interactivity Reexamined: A Baseline Analysis of Early Business Web Sties. Journal of Broadcasting and Electronic Media 4 (Fall) : 457-474.

Khermouch, Gerry, Tom Lowry. 2001. The Future of Advertising. Business Week 3/26/01: 138 .

Olmstead, Sylvia M. Chan, Jung Suk Park. 2000. From On-Air to Online World: Examining the Content and Structures of Broadcast TV Stations' Web Sites. Journalism and Mass Communication Quarterly 2 (Summer) : 321-339.

Papacharissi, Zizi, Alan M. Rubin. 2000. Predictors of Internet Use. Journal of Broadcasting and Electronic Media 2 (Spring) : 175-196.

Rindegard, Johan. 1999. HTML is Still Key, but Design Skills and Teamwork are Also Vital. InfoWorld Magazine, 28 June, 21.

Schuyler, Michael. 2000. The Future of Web Design. Computers in Libraries Magazine, January, 20.

Scott, Sandra Davidson. 1995. The technological Challenge for Curriculum and Instruction. Journalism and Mass Communication Educator 2 (Summer) : 30-37.

Singer, Jane B., David Craig, Chris W. Allen, Virginia Whitehouse, Anelia Dimitrova, Keith P. Sanders. 1996. Attitudes of Professors and Students About New Media Technology. Journalism and Mass Communication Educator 1 (Spring) : 36-45.

Smith, Matthew J. 1999. Strands in the Web: Community-Building Strategies in Online Fanzines. Journal of Popular Culture 2 (Fall) : 87-97.

Sundar, S. Shyam, Sunetra Narayan, Rafael Obregon, Charu Uppal. 1998. Does Web Advertising Work? Memory for Print vs. Online Media. Journalism and Mass Communication Quarterly 4 (Winter) : 822-835. 
Adobe Photoshop User Guide for Macintosh and Windows. [1997]. Pantone Inc. Adobe ImageStyler User Guide for Mac OS and Windows. [1998]. Pantone Inc. Quark Express Reference Manual. [1993]. Quark Inc. 
APPENDIX 
Name:

Joumalism $191-\mathrm{K}$

Photoshop Test

The following three questions pertain to file saving and what format PhotoShop documents should be in for the appropriate use.

3. When selecting a format in PhotoShop if you want to print a document, you should choose what?

\section{A. RGB B.CMYK C.ADL D.PIXAR}

4. When selecting a format in PhotoShop that is best for web graphics, you should choose what?
A. CMYK
B. ADL
C. RGB
D.RAW

5. When Saving an Adobe PhotoShop document for the web you should save it as what two kinds of files?
A. Tiff and Eps
B. JPEG and Gif
C. Targa and IFF
D. Pict and Gif

Questions four and five pertain to using text in Photoshop

6. What is the appropriate definition of Kerning?
A. The amount of space between each letter B. The color of the words or letters typed $C$. The font size of letters typed. D. The amount of space below letters.

7. What is the definition of Leading?

3. The font size of the letters typed B. The amount of space between paragraphs $C$. The amount of space between sentences $D$. The color of the words or letters typed 
8. Layers should always be used when using PhotoShop for what reason.
A. Because they are cool
B. You can fix mistakes that you have made
C. Layers are never necessary there is no need for them. D. They allow you to change the color of a document.

9. This tool allows you to erase images and colors from your graphic or picture
A. Paint Bucket
B. Eye Dropper
C. Type Tool
D. Eraser Tool

3. This tool allows you to move objects on your screen.
A. Zoom tool
B. Paint bucket
C. Eye Dropper
D. Move tool

4. This tool allows you to sample a color already on you picture and use it in a different area.(we used this on the Clint Eastwood graphic).
A. Zoom Tool
B. Move Tool
C. Eye Dropper
D. Eraser tool

Bonus questions:

-1. Name our current president

2. What was the name of the movie in the Clint Eastwood graphic we worked on last week?
A. Dirty Harry
B. Hang 'em high
C. The Outlaw Josey Wales
D. Pale Rider

3. How many are in a bakers dozen?
A. 13
B. 12
C. 11
D. 14 
Name:

Quark Express Test

Journalism $191 \mathrm{~K}$

1. A US Letter document is what size?
A. $81 / 2 \times 11$
B. $81 / 2 \times 14$
C. $11 \times 17$
D. none of these are correct

2. A US Legal document is what size?
A. $81 / 2 \times 11$
B. $81 / 2 \times 14$
C. $11 \times 17$
D. None of these are correct

3. The move tool does not do which of the following:

A. Moves objects on your document B. Required to select the images on a document for editing. C. Required to move objects within object boxes D. The move tool does all of these things.

4. In order to place an object within an object box, you must first be selected on which tool?
A. The move tool
B. The text/handy tool
C. The text box tool
D. Object box tool

5. When importing a picture what command must be chosen after going under File
A. Get object
B. Get Picture
C. Import object
D. Import Picture

6. When importing pictures into Quark they should always be saved as what two formats?

7. If you are linking text together from one box to another which tool should be selected?

8. Before one can create text they must first draw a box using which tool?

9. In order to modify an object you must first select what command at the top of your computer screen?

Bonus Questions:

1. On Miami Vice what was the name of Crockett's (Don Johnson) pet alligator?

2. Name all four members (character names) of the A-team. 
3. Name the early 80s T.V. sitcom that had a little girl that was actually a robot. (if you get this I am highly impressed.)

4. Which President did Alex P. Keaton (Michael J. Fox) have an autographed picture of in his room on Family Ties? 
Name:

J $191 \mathrm{~K}$

HTML Test

1. What Does HTML stand for?

2. The brackets $<>$ that HTML code works through are called what ?

3. Every document must begin with what type of tag?

4. What does a Meta tag do?

Tell what the following tags do.

5. <TITLE>

6. <IMG SRC="eastwood.jpg">

7. $<\mathrm{A} \mathrm{HREF=http://www.wvu.edu}><\mathrm{IMG} \mathrm{SRG="eastwood.jpg}></ \mathrm{A}>$

8. $<\mathrm{H} 1>$

9. $\langle\mathrm{P}>$

10. $\langle\mathrm{BR}>$

Please circle TRUE of False for the following questions

11. When constructing a web-site it is important to have categories so that surfers can more easily navigate your site.

TRUE FALSE 
12. An example of a symbol that would catch the attention and immediately let the surfer know what the site is about would be Superman's S shield on a superman fan site.

\section{TRUE FALSE}

13. It is a bad idea to let surfers interact with your site, in the form of submitting ideas, or giving suggestions or responding to polls.

TRUE $\quad$ FALSE

14. You should never respond to suggestions that surfers have e-mailed you about your web-site.

\section{TRUE $\quad$ FALSE}

15. I is important to keep a site up-dated and fresh with new information as much as possible.

\section{TRUE $\quad$ FALSE}

Bonus Questions (More 80's trivia)

What was ALF's real name?

What kind of car was the General Lee on the Dukes of Hazzard?

On Miami Vice what city was Rico Tubbs a detective in before coming to Miami? 
Name:

Journalism 191-K

ImageStyler Test

Identify the description of the following tool

1. Creates type and lets you enter and edit text.
A. Type Tool
B. Crop Tool C. polygon tool
D. Rotate Tool

2. Fills layers and objects with the current color selected.
A. Hand Tool
B. Paint Bucket
C. Eyedropper Tool
D. Ellipse Tool

3. Moves the area being viewed within the composition window.

A. Hand Tool B. Eyedropper Tool C. Rotate Tool D. Skew Tool

4. Draws Squares and rectangles
A. Ellipse Tool B. Type Tool
C. Rectangle Tool
D. Crop Tool

5. Samples the color of layers and the style of objects.

A. Polygon Tool B. Selection Tool C. Hand Tool D. Eyedropper Tool

6. When saving an Imagestyler document it must be saved once as a normal document, then it must be exported as an HTML document before it will translate to the World Wide Web.

\section{TRUE FALSE}

7. Adding a rollover action to an object is usually a way to let the web user know that it is a link to another page etc.

\section{TRUE FALSE}

8. If you want to add an effect to an object in Imagestyler such as 3D or coloring you must choose the web palette.

\section{TRUE FALSE}

9. If you want to make an object or text link to another page you must enter that sites URL in the styles palette. 


\section{TRUE FALSE}

10. In order to import a picture into Imagestyler you must go to File then get picture.

\section{TRUE FALSE}

\section{Bonus:}

11. How many Cosby kids were there.

12. On family ties what was the name of the annoying next door neighbor kid that had a crush on Malari.

13. Name all 4 members of the A-TEAM 


\section{Vita}

Name: Randall Franklin Mull

Date of Birth: June 30, 1975

Place of Birth: Bluefield West Virginia

Parents: Robert Franklin Mull, Rebecca Jean Bebout

\section{Degrees Earned:}

West Virginia University, Morgantown, WV

Bachelor of Arts in History, 1999;

West Virginia University, Morgantown, WV

Master of Science in Journalism, 2001. 